\title{
Possible wave formation and martensitic transformation of iron particles in copper single crystals during argon ion bombardment
}

Thölén, Anders Ragnar; Li, Chang-Hai; Easterling, K.E.

Published in:

Journal of Applied Physics

Link to article, DOI:

$10.1063 / 1.332112$

Publication date:

1983

Document Version

Publisher's PDF, also known as Version of record

Link back to DTU Orbit

Citation (APA):

Thölén, A. R., Li, C-H., \& Easterling, K. E. (1983). Possible wave formation and martensitic transformation of iron particles in copper single crystals during argon ion bombardment. Journal of Applied Physics, 54(2), 1067-1070. https://doi.org/10.1063/1.332112

\section{General rights}

Copyright and moral rights for the publications made accessible in the public portal are retained by the authors and/or other copyright owners and it is a condition of accessing publications that users recognise and abide by the legal requirements associated with these rights.

- Users may download and print one copy of any publication from the public portal for the purpose of private study or research.

- You may not further distribute the material or use it for any profit-making activity or commercial gain

- You may freely distribute the URL identifying the publication in the public portal 


\title{
Possible wave formation and martensitic transformation of iron particles in copper single crystals during argon ion bombardment
}

\author{
A. R. Thölén \\ Laboratory of Applied Physics I, Technical University of Denmark, 2800 Lyngby, Denmark \\ Chang-Hai Li and K. E. Easterling \\ Department of Engineering Materials, University of Luleå, 95187 Luleå, Sweden
}

(Received 19 February 1982; accepted for publication 27 October 1982)

\begin{abstract}
Thin single crystal copper specimens (thickness $\sim 250 \mathrm{~nm}$ ) containing coherent iron particles (diameter $40-50 \mathrm{~nm}$ ) have been bombarded with argon ions $(5,80$, and $330 \mathrm{keV}$ ). During this process some of the iron particles transform to martensite. The transformation was observed near the exposed surface and sometimes also close to the other surface but never in between. This is interpreted in terms of mechanical waves starting from the impact area.
\end{abstract}

PACS numbers: 79.20.Nc, 62.30. + d, 81.30.Kf

Martensitic transformation is normally an extremely fast process and does not therefore lend itself easily to a direct study, but one has to rely on a comparison of the start and end products. Another complication to any martensite investigation is the fine scale of the transformation, often with a dense twinning. This puts a limit even to electron microscopy methods and makes it difficult to distinguish the different stages of the process. One way to circumvent this problem is to study small, isolated particles. ${ }^{1-7}$ For example, this has been done for iron particles contained in a copper matrix..$^{2-5}$ By plastic deformation of the copper matrix martensite transformation is induced within the iron particles. Martensite transformation has also been studied in extracted small iron particles ${ }^{6}$ and in gas evaporated cobalt particles. ${ }^{7}$

Electron irradiation in a high voltage electron microscope $(650 \mathrm{keV})$ has been tried as an alternative to plastic deformation to initiate martensitic transformation in small particles, but with a negative result. ${ }^{3}$

This paper deals with argon ion bombardment of thinned copper single crystals containing spherical coherent fcc iron precipitates with a diameter of $40-50 \mathrm{~nm}$. The total iron content is $1.25 \mathrm{wt}$. \%. The alloy was made by a method described earlier ${ }^{2}$ and was subsequently thinned down to electron microscope specimen thickness at $-60^{\circ} \mathrm{C}$ using a nitric acid-methanol solution. The specimens were then bombarded with 5 (with an ion beam miller), 80 , and $330 \mathrm{keV}$ argon ions with total doses of $4 \times 10^{14}, 10^{12}$, and $10^{12}$ ions/ $\mathrm{cm}^{2}$, respectively. The ions were striking the foil to within 5$10^{\circ}$ of a $\langle 112\rangle$ direction for $5,20.5$, and $20.5 \mathrm{~s}$, respectively.

During bombardment some of the particles lost their coherency and transformed martensitically, as seen by the banding in the particles (Fig. 1). The transformation to martensite was sometimes partial, sometimes complete, as was checked with electron diffraction. The particles at the surface were more prone to complete transformation. These features here are identical to those observed in the plastically deformed $\mathrm{Cu}-\mathrm{Fe}$ alloys, as well as in extracted particles.

The depth distribution of the individual transformed and untransformed iron particles, as well as the damage loops, was determined by careful stereo microscopy and the results for 5 and $80 \mathrm{keV}$ ions are shown in Fig. 2. In both cases damage loops were observed inwards from the bom-
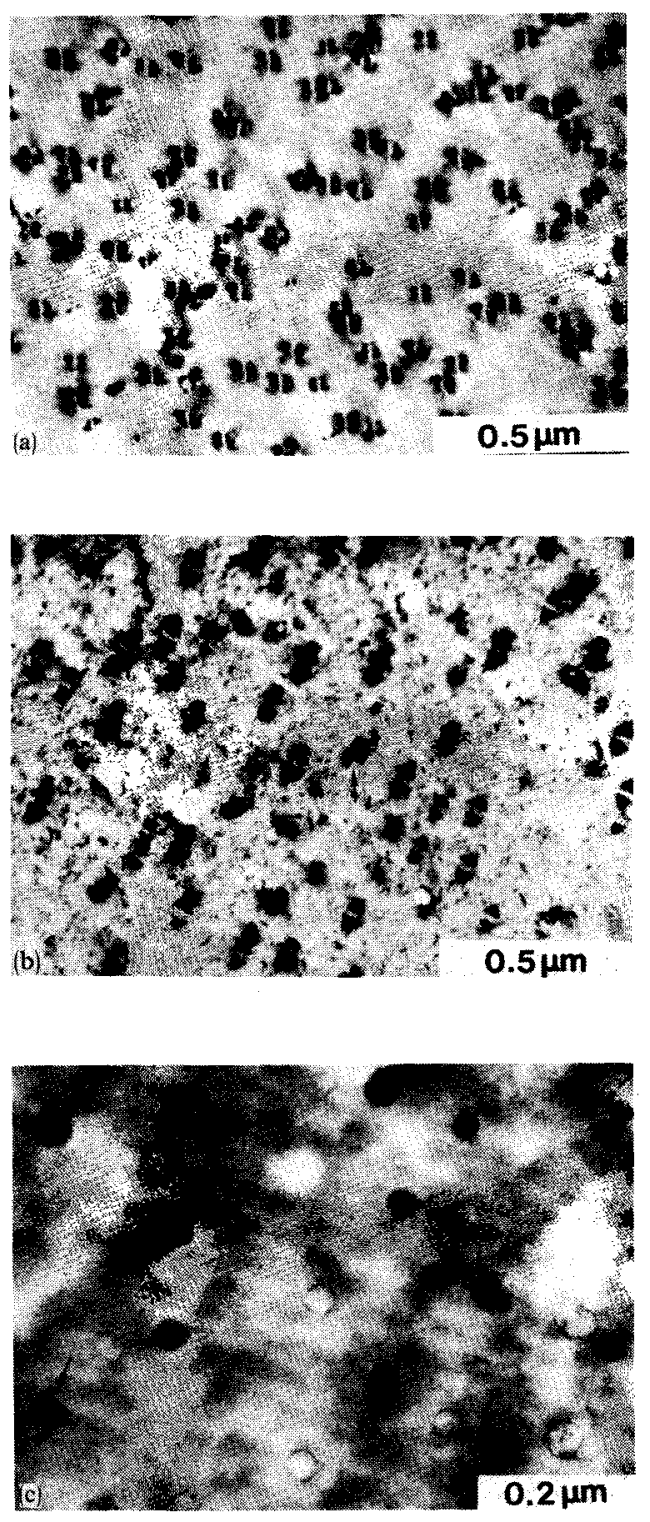

FIG. 1. (a) Coherent precipitates of $\gamma$-Fe in a copper matrix, $\mathrm{Cu} 1.25 \mathrm{wt} . \%$ Fe. Solution heat treated at $1040^{\circ} \mathrm{C}$ for $1 \mathrm{~h}$, quenched into water; precipitation treated at $700^{\circ} \mathrm{C}$ for $7 \mathrm{~h}$. The mean diameter of particles is $40-50 \mathrm{~nm}$. (b) Precipitates $(40-50 \mathrm{~nm})$ after bombardment by argon ions at $5 \mathrm{kV}$. Transformed precipitate indicated. (c) Transformed particles. Kinematical conditions in the matrix. Note banding in two of the particles. 

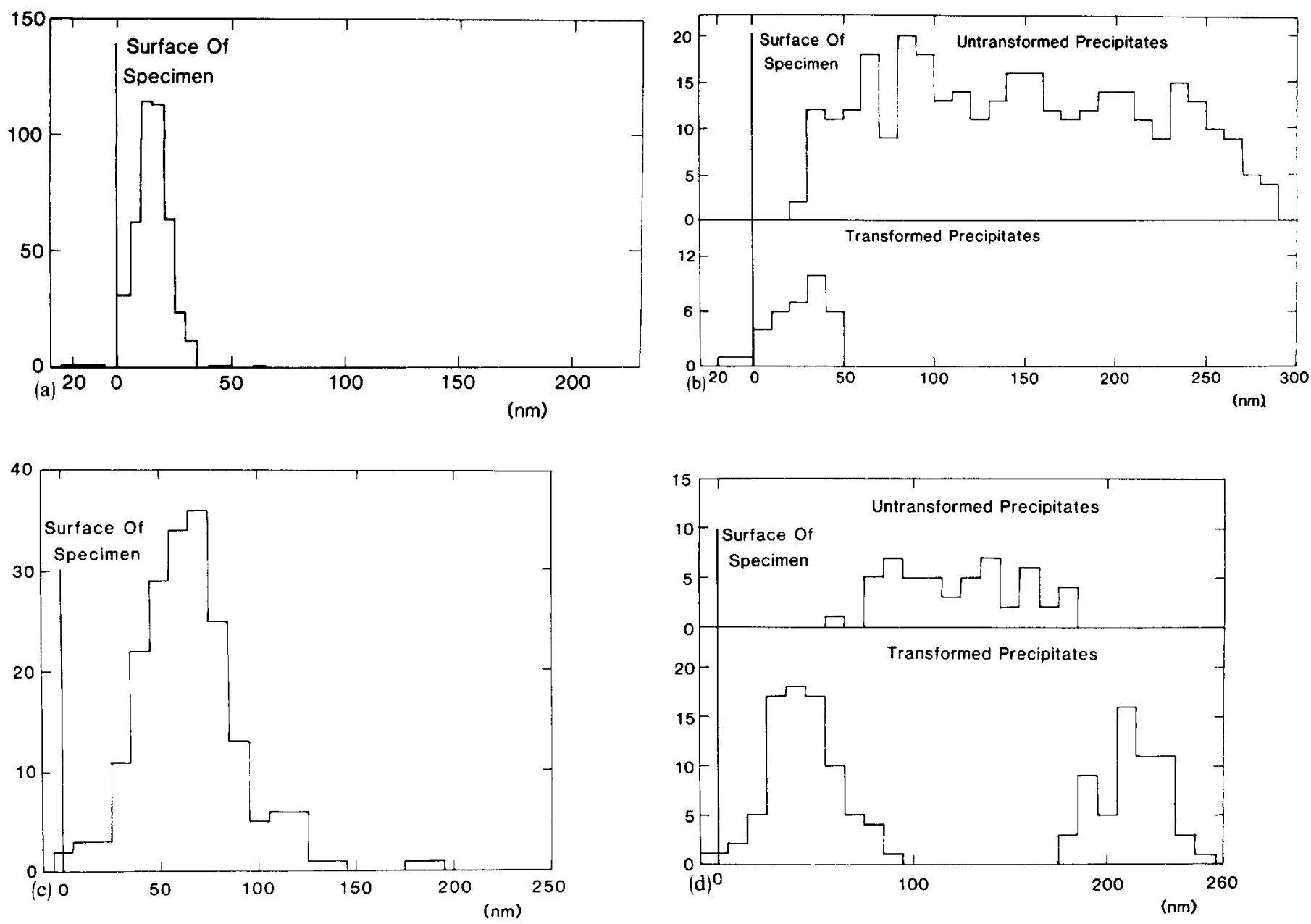

FIG. 2. (a) Depth distribution of the damage loops for a specimen bombarded at $5 \mathrm{keV}$. (b) Depth distribution of the transformed and untransformed iron precipitates. Same specimen as in (a). (c) Depth distribution of the damage loops for a specimen bombarded at $80 \mathrm{keV}$. (d) Depth distribution of the transformed and untransformed iron precipitates. Same specimen as in (c).

barded (top) surface (much more in the 80-keV case), as well as transformed particles, but there the similarity ends. What is totally unexpected is the distribution of the transformed particles. In the $5-\mathrm{keV}$ case, transformed particles were seen near the top surface extending somewhat further down than the damage loops. In the case of $80 \mathrm{keV}$ ions the damage goes down to about half the specimen thickness $(\sim 250 \mathrm{~nm})$ and transformed iron particles are seen near the top and bottom surfaces. In between there are no transformed particles. In addition, it looks as if there are fewer particles visible in the central areas than there were before the bombardment. This remains a mystery, but it can possibly be due to a loss of coherency without martensitic transformation.

At $330 \mathrm{keV}$ no detailed measurements have been performed but the impression is that the ion beam damage has gone right through the foil and that the transformed particles are limited to the top and bottom surfaces.

It is a very strange and unexpected result that transformation of the particles occur at the top and bottom surfaces but not in the center. There seems to be three possible explanations for this result.

The first possibility would be that when the incoming ion dissipates its momentum, this is in fact equivalent to a force acting on the thin foil. A calculation using the relevant data, however, gives stresses which are all too small to cause any deformation $\left(\sim 10^{-5} \mathrm{~N} / \mathrm{m}^{2}\right)$. Also, the bend stresses in the foil which appear due to this oneside loading are too small to cause severe deformation and moreover there should be no difference between top and bottom surfaces.

A second possibility would be that implanted excess material gives rise to stresses. ${ }^{8}$ These stresses would then be largest at the top (and the bottom) surface. The surface stress obtained with $100 \mathrm{keV}$ argon ions (dose $10^{16}-10^{17}$ ions $/ \mathrm{cm}^{2}$ ) in a steel ${ }^{8}$ is $50 \times 10^{9} \mathrm{~N} / \mathrm{m}^{2}$. This stress drops heavily with the dose; so with the doses involved here the stresses would be very small.

The third and only possibility which seems to be left is that a wave is launched from the point of impact, causing some of the metastable particles to transform in the neighborhood and further out. The possibility of waves sent out at ionic impact has been raised and debated recently. ${ }^{9,10} \mathrm{~A}$ computer simulation of argon ion impact at $5 \mathrm{keV}$ at a copper surface also showed evidence of a shock wave. ${ }^{11}$

Firstly, one should consider the energy and momentum 
TABLE I. Table shows the particle velocity of the wave in the forward direction $(u)$, the energy transmitted in the forward direction $W_{2}$, the stress levels $\sigma=\rho v_{2} u$ (using $v_{2}=5000 \mathrm{~m} / \mathrm{s}$ ) and also the number of atoms participating in the wave, $N$. The results for four different $u / v_{1}$ values are shown. The $u / v_{1}$ values gives the relative energy, which is transferred into the forward wave.

\begin{tabular}{|c|c|c|c|c|c|c|c|c|c|c|}
\hline \multirow[b]{2}{*}{$u / v_{1}$} & \multirow[b]{2}{*}{$N$} & \multicolumn{3}{|c|}{$W_{1}=5 \mathrm{keV}$} & \multicolumn{3}{|c|}{$W_{1}=80 \mathrm{keV}$} & \multicolumn{3}{|c|}{$W_{1}=330 \mathrm{keV}$} \\
\hline & & $\begin{array}{l}u \\
(\mathrm{~m} / \mathrm{s})\end{array}$ & $\begin{array}{l}W_{2} \\
(\mathrm{Nm})\end{array}$ & $\begin{array}{l}\bar{\sigma} \\
\left(\mathrm{N} / \mathrm{m}^{2}\right)\end{array}$ & $\begin{array}{l}u \\
(\mathrm{~m} / \mathrm{s})\end{array}$ & $\begin{array}{l}W_{2} \\
(\mathrm{Nm})\end{array}$ & $\begin{array}{l}\sigma \\
\left(\mathrm{N} / \mathrm{m}^{2}\right)\end{array}$ & $\begin{array}{l}u \\
(\mathrm{~m} / \mathrm{s})\end{array}$ & $\begin{array}{l}W_{2} \\
(\mathbf{N m})\end{array}$ & $\begin{array}{l}\sigma \\
\left(\mathbf{N} / \mathbf{m}^{2}\right)\end{array}$ \\
\hline $10^{-1}$ & 6.3 & $1.5 \times 10^{4}$ & $8.0 \times 10^{-17}$ & $7 \times 10^{11}$ & $6.2 \times 10^{4}$ & $1.3 \times 10^{-15}$ & $3 \times 10^{12}$ & $1.3 \times 10^{5}$ & $5.3 \times 10^{-15}$ & $6 \times 10^{12}$ \\
\hline $10^{-3}$ & $6.3 \times 10^{2}$ & $1.5 \times 10^{2}$ & $8.0 \times 10^{-19}$ & $7 \times 10^{9}$ & $6.2 \times 10^{2}$ & $1.3 \times 10^{-17}$ & $3 \times 10^{10}$ & $1.3 \times 10^{3}$ & $5.3 \times 10^{-17}$ & $6 \times 10^{10}$ \\
\hline $10^{-5}$ & $6.3 \times 10^{4}$ & 1.5 & $8.0 \times 10^{-21}$ & $7 \times 10^{7}$ & 6.2 & $1.3 \times 10^{-19}$ & $3 \times 10^{3}$ & $1.3 \times 10^{1}$ & $5.3 \times 10^{-19}$ & $6 \times 10^{8}$ \\
\hline $10^{-7}$ & $6.3 \times 10^{6}$ & $1.5 \times 10^{-2}$ & $8.0 \times 10^{-23}$ & $7 \times 10^{5}$ & $6.2 \times 10^{-2}$ & $1.3 \times 10^{-21}$ & $3 \times 10^{6}$ & $1.3 \times 10^{-1}$ & $5.3 \times 10^{-21}$ & $6 \times 10^{6}$ \\
\hline
\end{tabular}

balance at impact

$$
\begin{aligned}
& W_{1}=W_{2}+W_{3}, \\
& p_{1}=p_{2},
\end{aligned}
$$

where $W_{1}$ is the energy of the incoming ion, $W_{2}$ the energy of the outgoing wave in the forward direction, $W_{3}$ the energy lost due inelastic collisions and scattering in a nonforward direction, $v_{1}$ the velocity of the incoming ion, $v_{2}$ the wave velocity in the solid, $u$ the particle velocity of wave in forward direction, $p_{1}$ the momentum of the incoming ion, $p_{2}$ the momentum of the wave in the forward direction, and $\rho$ the density of the solid.

Once $u / v_{1}$ is known, it is possible to solve $W_{2}\left(=W_{1} \times u / v_{1}\right)$ and also to find the stress levels $\sigma$ near impact, using $\sigma=\rho v_{2} u$. Without knowing any details about the wave, we have made the calculations for four different situations $\left(u / v_{1}\right.$ values) (Table I). It is observed that in several cases the stresses reach substantial values being in many cases a large fraction of the elastic moduli. Unfortunately, we are at this stage not able to tell the exact $u / v_{1}$ level, nor whether this is the same for the three energies.

Secondly, it is appropriate to consider elastic wave propagation in anisotropic media, as this includes some new concepts as compared to the isotropic case. ${ }^{12}$ In anisotropic media there are three different velocity surfaces, which

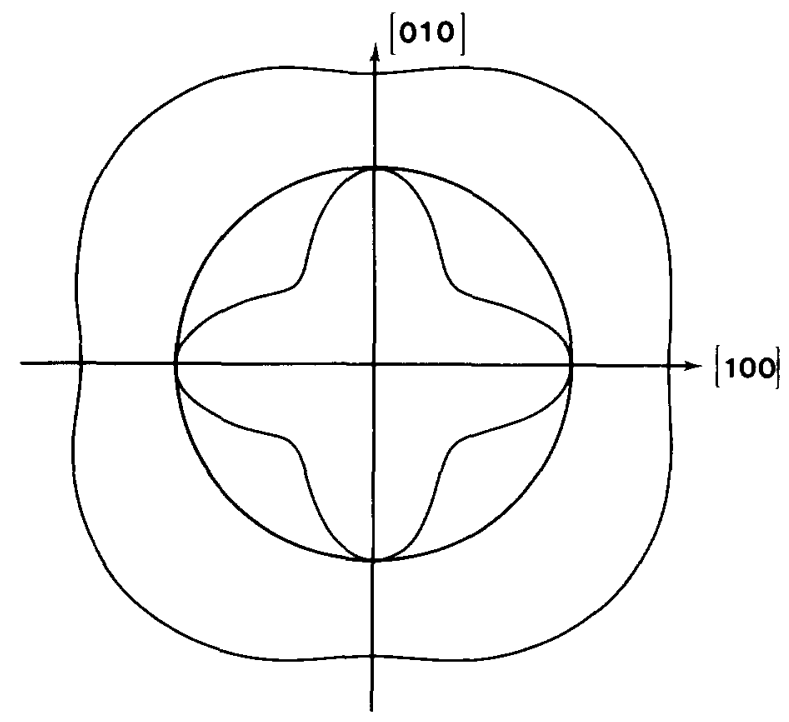

FIG. 3. Section perpendicular to [001] through the velocity surface of copper. Curves mark the three different wave velocities in each direction. means that in the general case three different wave velocities exist in each direction. In the isotropic case one distinguishes between a longitudinal wave with one velocity and two transversal waves polarized perpendicularly to the beam direction and with lower velocities. In the general anisotropic case the three waves are also polarized perpendicularly to each other but there exist no pure longitudinal or transversal waves. As an example, a [001] section through the velocity surfaces for copper is shown in Fig. 3. An important point now emerges. The energy transport does not take place in the same direction as the wave vector. To find the direction of energy transport, first construct the slowness surface which is the reciprocal of the velocity in each direction. $\mathbf{A}$ [001] section through the slowness surface is shown in Fig. 4. Now the group velocity which marks the direction of energy flow is given by the normal to these surfaces and it can easily be seen that some directions are favored; i.e., the energy travels preferentially in certain directions. This shows that the energy can be considered to be sent out as narrow rays which indicates that the available intensity does not fade off very rapidly on its way down the foil. The same type of arguments can be used for the surface (Rayleigh) waves. When a har-

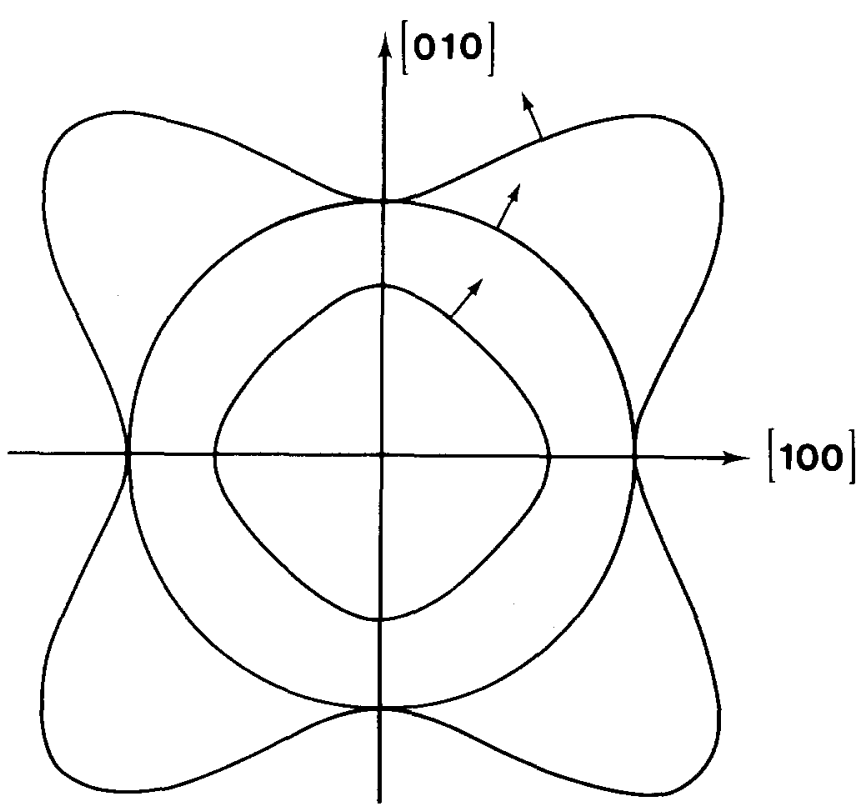

FIG. 4. Section perpendicular to [001] through the slowness surface of copper. Energy flow is always perpendicular to the surfaces as marked by arrows. 
monic farce, for example, is acting at the surface of a semiinfinite isotropic solid, waves are emitted into the solid and along the surface and a large proportion of the available energy follows the surface. There is every reason to believe that the same picture is true even in the case of impact on an anisotropic material, but now we also have the slowness curve for the Rayleigh waves to consider. This also leads to rays of energy leaving the impact area and these can also travel substantial distances without fading.

We have now found a mechanism to transport energy to coherent iron particles which then could transform martensitically from their metastable state; however, the picture is far from complete. Why does it happen at the lower surface at $80 \mathrm{keV}$ but not in the center? Does that depend on a reflection of a compressive wave into a tensile at the bottom surface which then could cause damage like in scabbing? Or does it depend on some other interaction phenomena between several waves, some of which are possibly reflected at the particles? Another possibility would be that surface waves were sent out which then proceeded to the electropolished hole and continued on the lower surface. Due to the limited penetration of a surface wave (less than a wavelength) this might also explain why the transformation is confined to the surface regions.

\section{ACKNOWLEDGMENTS}

The authors would like to thank Dr. G. Holmén for help with the ion bombardment and Dr. D. Porter, Dr. J. Field, and Dr. E. Johnson for valuable discussions. A more comprehensive report on this work will be published later.

${ }^{1}$ R. H. Cech and D. Turnbull, AIME Trans. 206, 124 (1956).

${ }^{2}$ K. E. Easterling and H. M. Miekk-Oja, Acta Metall. 15, 1133 (1967).

${ }^{3}$ K. R. Kinsman, G. Das, and R. F. Hehemann, Acta Metall. 25, 359 (1977).

${ }^{4}$ M. Kato, R. Monzen, and T. Mori, Acta Metall. 26, 605 (1978).

${ }^{5}$ K. E. Easterling and G. C. Weatherly, Acta Metall. 17, 845 (1969).

${ }^{6}$ K. E. Easterling and P. R. Swann, Acta Metall. 19, 117 (1971).

${ }^{7}$ A. R. Thölén, Surf. Sci. 106, $70(1981)$.

${ }^{8}$ N. E. W. Hartley, J. Vac. Sci. Technol. 12, 485 (1975)

${ }^{9}$ G. Carter, Rad. Eff. Lett. 50, 105 (1980).

${ }^{10} \mathrm{~K}$ : B. Winterbon, Rad. Eff. Lett. 57, 89 (1980).

"'R. P. Webb and D. E. Harrison, Jr., Appl. Phys. Lett. 39, 311 (1981).

${ }^{12}$ M. J. Musgrave, Crystal Acoustics (Holden-Day, San Francisco, 1970). 